\title{
Forsterite-hydroxyapatite composite scaffolds with photothermal antibacterial activity for bone repair
}

\author{
Weiye LIU ${ }^{a, b, \dagger}$, Rongtai ZUO ${ }^{c, \dagger}$, Tanglong $\mathrm{ZHU}^{a, b}$, Min $\mathrm{ZHU}^{a, *}$, \\ Shichang $\mathrm{ZHAO}^{c,}$, Yufang $\mathrm{ZHU}^{b, *}$ \\ ${ }^{a}$ School of Materials Science and Engineering, University of Shanghai for \\ Science and Technology, Shanghai 200093, China \\ ${ }^{b}$ State Key Laboratory of High Performance Ceramics and Superfine Microstructure, \\ Shanghai Institute of Ceramics, Chinese Academy of Sciences, Shanghai 200050, China \\ ${ }^{c}$ Department of Orthopedics, Shanghai Jiao Tong University affiliated Sixth People's Hospital, \\ Shanghai Jiao Tong University, Shanghai 200233, China
}

Received: December 26, 2020; Revised: March 16, 2021; Accepted: May 5, 2021

(c) The Author(s) 2021.

\begin{abstract}
Bone engineering scaffolds with antibacterial activity satisfy the repair of bacterial infected bone defects, which is an expected issue in clinical. In this work, 3D-printed polymer-derived forsterite scaffolds were proposed to be deposited with hydroxyapatite (HA) coating via a hydrothermal treatment, achieving the functions of photothermal-induced antibacterial ability and bioactivity. The results showed that polymer-derived forsterite scaffolds possessed the photothermal antibacterial ability to inhibit Staphylococcus aureus (S. aureus) and Escherichia coli (E. coli) in vitro, owing to the photothermal effect of free carbon embedded in the scaffolds. The morphology of HA coating on forsterite scaffolds could be controlled through changing the hydrothermal temperature and the $\mathrm{pH}$ value of the reaction solution during hydrothermal treatment. Furthermore, HA coating did not influence the mechanical strength and photothermal effect of the scaffolds, but facilitated the proliferation and osteogenic differentiation of rat bone mesenchymal stem cells (rBMSCs) on scaffolds. Hence, the HA-deposited forsterite scaffolds would be greatly promising for repairing bacterial infected bone defects.

Keywords: forsterite scaffolds; hydroxyapatite (HA) coating; bone repair; photothermal effect; antibacterial activity
\end{abstract}

\section{Introduction}

Bone defects caused by the postoperative infections,

\footnotetext{
$\dagger$ Weiye Liu and Rongtai Zuo contributed equally to this work.

* Corresponding authors.

E-mail: M. Zhu,mzhu@usst.edu.cn;

S. Zhao, zhaoshichang0404@163.com;

Y.Zhu, zjf2412@163.com
}

injuries, osteoporosis, bone tumors, and other diseases are a serious problem in clinical [1]. Generally, the repair of critical-sized bone defects should be helped with bone repair materials [2]. Among them, silicatebased bioceramics, such as bioglass, calcium silicate, akermanite, and bredigite, have received increasing attention to treat bone defects due to their high bioactivity [3-6]. Forsterite $\left(\mathrm{Mg}_{2} \mathrm{SiO}_{4}\right)$ as one type of silicate-based bioceramics also has great potential for load-bearing 
bone repair owing to their biocompatibility, excellent mechanical property, and slow biodegradation behavior [7]. Choudhary et al. [8] fabricated cylindrical forsterite scaffolds by molding forsterite powder and sintering, and the compressive strength and Young's modulus of forsterite scaffolds were $201 \mathrm{MPa}$ and $4.8 \mathrm{GPa}$, respectively. Such mechanical property could match with the cortical bones. Hence, forsterite can be used as a potential material for bone repair in load-bearing areas $[9,10]$.

Recently, the combination of organosilicon polymerderived ceramics (PDCs) strategy with 3D printing has been demonstrated to fabricate silicate ceramic scaffolds [11]. We also developed to fabricate forsterite scaffolds by $3 \mathrm{D}$ printing of silicone resin/MgO precursor and sintering in an inert atmosphere [12]. Such forsterite scaffolds exhibited photothermal-induced antibacterial activity due to the embedded free carbon in the scaffolds $[12,13]$. However, the relatively poor bioactivity of forsterite would affect its osteogenesis ability [14]. To address this issue, an efficient strategy is developed to modify the surface of forsterite scaffolds with bioactive materials, which could stimulate cell responses of bone mesenchymal stem cells (BMSCs) including cell adhesion, proliferation, and osteogenic differentiation, thereby promoting bone repair $[15,16]$.

HA, one main mineral composition of human bones, possesses the outstanding bioactivity and biocompatibility, which has become one of the most popular bioactive materials to modify the metal implants [17]. Nowadays, some coating techniques, such as electrophoretic deposition and plasma spraying, have been applied to produce uniform HA coatings on the implants and scaffolds $[18,19]$. Studies demonstrated that the coating morphology and bonding strength between the coating and matrix material are crucial for cell response and in vivo bone integration [20].

Recently, hydrothermal method was increasingly developed to fabricate HA coating on the scaffolds for improving the performance of scaffolds [21,22]. Studies demonstrated that hydrothermal method could controllably synthesize HA with different morphologies including whiskers, microspheres, nanorods, and nanowires [23,24]. Zhang et al. [25] reported the utilization of calcium nitrate and diammonium hydrogen phosphate as raw materials to synthesize HA by a hydrothermal method, and different morphological HA could be synthesized by controlling the $\mathrm{pH}$ values of the reaction solutions during hydrothermal treatments.
On the other hand, hydrothermal method can induce HA nucleation on the active sites of matrix materials, and further promate to grow and crystallize, which facilitates HA to bond on the surface of matrix materials [26].

Hence, hydrothermal method has been developed to deposit HA coating on the surface of scaffolds. Yang et al. [27], as an illustration, deposited an HA coating with a controllable nanostructure on the surface of a 3D-printed pure iron scaffold by a hydrothermal method. The results demonstrated that the mechanical performances of the composite scaffolds were comparable to natural bones. The HA coating was highly bonded to the substrate materials, and significantly promoted cell response of rBMSCs. Similarly, Hu et al. [28] used a hydrothermal method to deposit nano HA with rod-like morphology on porous biphasic calcium phosphate (BCP) scaffolds, and achieved better osteogenic differentiation of BMSCs compared with pure BCP scaffolds. It indicated that a hydrothermal method to deposit HA coating could be an efficient strategy to enhance the bioactivity of scaffolds for bone repair.

In this study, we proposed to deposit HA coating on the surface of 3D-printed polymer-derived forsterite scaffolds by a hydrothermal method to improve the bioactivity. On one hand, the morphology and size of HA coating could be regulated by changing the $\mathrm{pH}$ value and hydrothermal temperature. On the other hand, HA coating did not destroy the structure and influence the photothermal effect of scaffolds owing to the excellent stability of forsterite scaffolds. Hence, the HA-coated forsterite scaffolds would be promising for repair bone defects with bacterial infection.

\section{Experimental}

\section{1 Materials}

All raw materials were utilized without further purification including a commercial silicone resin (SilresMK, Wacker Chemie, Germany), isopropyl alcohol, magnesium oxide $(\mathrm{MgO}, \geqslant 99.5 \%)$, ethylene diamine tetraacetic acid disodium salt (EDTA-2Na, $\geqslant 99.5 \%$ ), diammonium phosphate $\left(\left(\mathrm{NH}_{4}\right)_{2} \mathrm{HPO}_{4}, \geqslant 99.0 \%\right)$, tetrahydrate calcium nitrate $\left(\mathrm{Ca}\left(\mathrm{NO}_{3}\right)_{2} \cdot 4 \mathrm{H}_{2} \mathrm{O}\right.$, 98.5\%), urea $\left(\mathrm{CO}\left(\mathrm{NH}_{2}\right)_{2}\right.$, $\geqslant 99.0 \%$ ), and sodium hydroxide $(\mathrm{NaOH}, \geqslant 96.0 \%)$, which were all purchased from Sinopharm Chemical Reagent Co., Ltd., China. 


\section{2 Fabrication of HA-coated forsterite $\left(\mathrm{M}_{2} \mathrm{~S}-\mathrm{HA}\right)$ scaffolds}

The 3D-printed silicone resin-derived forsterite $\left(\mathrm{Mg}_{2} \mathrm{SiO}_{4}\right.$, $\mathrm{M}_{2} \mathrm{~S}$ ) scaffolds were fabricated after sintering at $1400{ }^{\circ} \mathrm{C}$ in a continuous argon atmosphere on the basis of our previous report [12]. HA deposition on forsterite scaffolds was successfully treated via a hydrothermal method. Typically, $11.8 \mathrm{~g}$ of $\mathrm{Ca}\left(\mathrm{NO}_{3}\right)_{2} \cdot 4 \mathrm{H}_{2} \mathrm{O}$ and $18.61 \mathrm{~g}$ of EDTA-2Na were completely dissolved in $500 \mathrm{~mL}$ deionized water, and $3.96 \mathrm{~g}$ of $\left(\mathrm{NH}_{4}\right)_{2} \mathrm{HPO}_{4}$ and $15.15 \mathrm{~g}$ of $\mathrm{CO}\left(\mathrm{NH}_{2}\right)_{2}$ were subsequently added. After stirring to dissolve completely, $\mathrm{NaOH}$ liquor $(1 \mathrm{~mol} / \mathrm{L})$ was used to regulate the $\mathrm{pH}$ value of the mixed solution reaching 6. Next, the above mixed solution $(45 \mathrm{~mL})$ was transferred into a $70 \mathrm{~mL}$ Teflon autoclave, and five $\mathrm{M}_{2} \mathrm{~S}$ scaffolds were put in it. A hydrothermal treatment was conducted at $160{ }^{\circ} \mathrm{C}$ for $10 \mathrm{~h}$ before cooling to room temperature, and the HA-deposited $\mathrm{M}_{2} \mathrm{~S}$ $\left(\mathrm{M}_{2} \mathrm{~S}-\mathrm{HA}\right)$ scaffolds were ultrasonically treated in deionized water bath for $30 \mathrm{~s}$ and rinsed with ethanol. The final scaffolds were then oven-dried at $100{ }^{\circ} \mathrm{C}$. The $\mathrm{pH}$ values of the mixed solution $(4,6,8$, and 10) and hydrothermal temperatures $\left(140,160,180\right.$, and $\left.200{ }^{\circ} \mathrm{C}\right)$ were changed to investigate the phase, morphology, and structure of HA coating.

\section{3 Characterization}

The phases of scaffolds were characterized by wide-angle X-ray diffraction (XRD) measured with a Bruker D8 ADVANCE X-ray powder diffractometer (Bruker Corp, Billerica, MA, USA). The surface morphology of HA coating on forsterite scaffolds was observed and analyzed by a scanning electron microscope (SEM, FEI Quanta 450, USA). A static material testing machine $(2.5 \mathrm{kN}$, Zwick Roell, Germany) was utilized to measure the compressive strength of scaffolds. The overall porosity of scaffolds was measured using traditional Archimedes principle according to Ref. [3].

\section{4 Photothermal effect of scaffolds}

The photothermal effect of scaffolds was detected with an infrared thermal imager (FLIRTM A325SC camera, USA) after an $808 \mathrm{~nm}$ laser irradiation. The real-time surface temperature changes of each $\mathrm{M}_{2} \mathrm{~S}$ or $\mathrm{M}_{2} \mathrm{~S}-\mathrm{HA}$ scaffold were tested after laser irradiation at different power densities $\left(0.5,0.75\right.$, and $\left.1.0 \mathrm{~W} / \mathrm{cm}^{2}\right)$ and in different environmental conditions (in air for dry condition and in phosphate buffer solution (PBS) for wet condition), respectively. The photothermal stabilities of scaffolds were analyzed after three cycles with a laser "on and off" state at a power density of $1.0 \mathrm{~W} / \mathrm{cm}^{2}$.

\section{5 Cell response of $r B M S C s$ on $M_{2} S-H A$ scaffolds}

In this study, the third-generation rBMSCs were used to evaluate cell response on $\mathrm{M}_{2} \mathrm{~S}-\mathrm{HA}$ scaffolds. Firstly, the $\mathrm{M}_{2} \mathrm{~S}$ and $\mathrm{M}_{2} \mathrm{~S}-\mathrm{HA}$ scaffolds sterilized by dry heating at $200{ }^{\circ} \mathrm{C}$ for $2 \mathrm{~h}$ were put in 24-well plates, and $1.0 \times 10^{5}$ cells were seeded on each scaffold. Subsequently, the rBMSCs-seeded scaffolds were placed in an incubator $\left(5 \% \mathrm{CO}_{2}, 37{ }^{\circ} \mathrm{C}\right)$ for $2 \mathrm{~h}$ to allow the cell attachment on the scaffolds, and then added $1 \mathrm{~mL}$ culture medium in each well for continuing the culture.

The proliferation of rBMSCs on scaffolds was evaluated by a Cell Counting Kit-8 (CCK-8) assay, which was determined by measuring the absorbance at a wavelength of $450 \mathrm{~nm}$ with a microplate reader (Bio-Rad680, USA). Furthermore, the distribution of rBMSCs with fluorescence labeling was observed by a confocal laser scanning microscope (CLSM, Leica, Germany). Cell nuclei and cytoskeleton of rBMSCs were stained with $10 \mathrm{mg} / \mathrm{mL} \mathrm{4',6-diamidino-2-phenylindole}$ (DAPI, Yeasen, China) and $5 \mathrm{mg} / \mathrm{mL}$ rhodamine phalloidin (Yeasen, China) for $5 \mathrm{~min}$, respectively.

The alkaline phosphatase (ALP) activity of rBMSCs on scaffolds was tested by an ALP assay kit. Firstly, $1.0 \times 10^{5} \mathrm{rBMSC}$ were seeded on each $\mathrm{M}_{2} \mathrm{~S}$ or $\mathrm{M}_{2} \mathrm{~S}-\mathrm{HA}$ scaffold, and the culture medium was renewed every two days [29]. When cultured for 7 and 14 days, the culture medium was removed and the attached cells were gently rinsed with PBS for three times and with cold Tris buffer $(50 \mathrm{mM})$ once. Next, the cells were lysed using a $0.2 \%$ Triton X-100 $(200 \mu \mathrm{L})$, and the lysates were sonicated to disperse after being centrifuged for $15 \min \left(14,000 \mathrm{rpm}, 4{ }^{\circ} \mathrm{C}\right)$. Afterward, $50 \mu \mathrm{L}$ of supernatant was mixed with $150 \mu \mathrm{L}$ working solution on the basis of the supplier's protocol for determining. The conversion of p-nitrophenylphosphate into p-nitrophenol in the presence of ALP was determined by the absorbance at $405 \mathrm{~nm}$ measured with a microplate reader. The ALP activity was calculated from a standard curve after normalizing to the total protein content.

Real-time quantitative reverse transcription-polymerase chain reaction (qPCR) was utilized to detect the related osteogenic gene expression of rBMSCs on both types of scaffolds including genes collagen type I (COL-1), osteocalcin $(\mathrm{OCN})$, runt-related transcription factor 2 
(RUNX2), and ALP. The expression level of genes was normalized by the glyceraldehyde-3- phosphate dehydrogenase (GAPDH), and the results were estimated with reference to $2^{\Delta \Delta C t}$ method according to Ref. [30].

\section{6 In vitro photothermal antibacterial ability of scaffolds}

Staphylococcus aureus (S. aureus) and Escherichia coli (E. coli), as the representative Gram-positive and Gram-negative bacteria, were used to investigate in vitro antibacterial ability of $\mathrm{M}_{2} \mathrm{~S}-\mathrm{HA}$ scaffolds. $\mathrm{M}_{2} \mathrm{~S}$ scaffolds were used as a control. The antibacterial efficiency of $\mathrm{M}_{2} \mathrm{~S}$ or $\mathrm{M}_{2} \mathrm{~S}-\mathrm{HA}$ scaffolds with or without an $808 \mathrm{~nm}$ laser irradiation was determined by a spread plate counting method [31], and the operation procedures were followed as Ref. [12].

\section{7 Statistical analysis}

The results were expressed as the mean \pm standard deviation (SD), which were based on the data from three rational parallel experiments. The one-way ANOVA and Student-Newman-Keuls post hoc tests were used to determine the level of significance and $P$ values $<0.05$ were commonly deemed to be significant.

\section{Results and discussion}

The structure, surface macro/micro morphology, and phase change can be directly reflected by simple physical and chemical characterization. Figure 1 shows the representative photographs and XRD patterns of $\mathrm{M}_{2} \mathrm{~S}$ and $\mathrm{M}_{2} \mathrm{~S}-\mathrm{HA}$ scaffolds. It can be seen that $\mathrm{M}_{2} \mathrm{~S}$ scaffold became rougher and the scaffold color changed from black to gray after HA coating (Figs. 1(a) and 1(b)), suggesting the deposition of white $\mathrm{HA}$ on $\mathrm{M}_{2} \mathrm{~S}$ scaffolds was successfully achieved via a simple hydrothermal process. XRD technique was simultaneously utilized to further confirm HA coating on the surface of scaffolds by analyzing the phases of $\mathrm{M}_{2} \mathrm{~S}$ scaffolds before and after hydrothermal treatments. As shown in Fig. 1(c), only the diffraction peaks of forsterite phase (JCPDS Card 34-0189) were observed for $\mathrm{M}_{2} \mathrm{~S}$ scaffolds; however, the diffraction peaks of HA phase (JCPDS Card 09-0432) also appeared on $\mathrm{M}_{2} \mathrm{~S}-\mathrm{HA}$ scaffolds except for the diffraction peaks of forsterite phase. It obviously revealed that $\mathrm{HA}$ could deposit on $\mathrm{M}_{2} \mathrm{~S}$
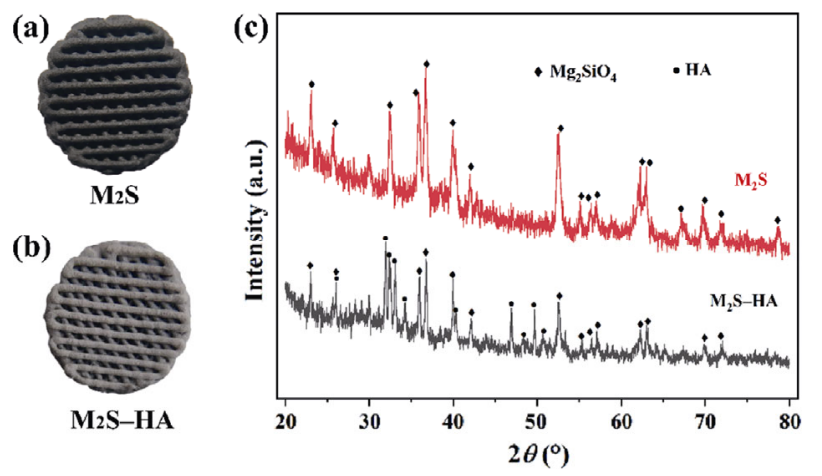

Fig. 1 Optical photographs of (a) $\mathrm{M}_{2} \mathrm{~S}$ and (b) $\mathrm{M}_{2} \mathrm{~S}-\mathrm{HA}$ scaffolds; (c) XRD patterns of $\mathrm{M}_{2} \mathrm{~S}$ and $\mathrm{M}_{2} \mathrm{~S}$-HA scaffolds.

scaffolds well to form $\mathrm{M}_{2} \mathrm{~S}-\mathrm{HA}$ scaffolds through a hydrothermal process.

To optimize the nucleation and growth state of HA coating on $\mathrm{M}_{2} \mathrm{~S}$ scaffolds, the effects of $\mathrm{pH}$ value of the reaction solution and hydrothermal temperature on HA coating were subsequently investigated in this study. Here, $\mathrm{Ca}\left(\mathrm{NO}_{3}\right)_{2} \cdot 4 \mathrm{H}_{2} \mathrm{O}$ and $\left(\mathrm{NH}_{4}\right)_{2} \mathrm{HPO}_{4}$ were utilized as the $\mathrm{Ca}$ and $\mathrm{P}$ sources for HA coating by a hydrothermal treatment, and the ratio of $\mathrm{Ca}$ to $\mathrm{P}$ was precisely adjusted to be 1.67 which is consistent with natural HA. Figure 2 shows the XRD patterns of the $\mathrm{M}_{2} \mathrm{~S}-\mathrm{HA}$ scaffolds that were hydrothermally treated at $140-200{ }^{\circ} \mathrm{C}$ when $\mathrm{pH}$ values were from 4 to 10 . The HA phase almost could not be observed for $\mathrm{M}_{2} \mathrm{~S}-\mathrm{HA}$ scaffolds while the reaction condition was set to $\mathrm{pH}=6$ and hydrothermally treated at $140{ }^{\circ} \mathrm{C}$, but $\mathrm{M}_{2} \mathrm{~S}-\mathrm{HA}$ scaffolds that were hydrothermally treated at 160,180 , and $200{ }^{\circ} \mathrm{C}$ obviously exhibited the diffraction peaks of HA phase, indicating the HA deposition on $\mathrm{M}_{2} \mathrm{~S}$ scaffolds. On the other hand, the diffraction peak intensities of HA were similar for $\mathrm{M}_{2} \mathrm{~S}-\mathrm{HA}$ scaffolds hydrothermally treated at 160,180 , and $200{ }^{\circ} \mathrm{C}$, suggesting that the deposited HA with parallel crystallinity could be obtained at the hydrothermal temperatures of $160-200{ }^{\circ} \mathrm{C}$. It can also be seen that HA could deposit on $\mathrm{M}_{2} \mathrm{~S}$ scaffolds at a hydrothermal temperature of $160{ }^{\circ} \mathrm{C}$ when $\mathrm{pH}$ value of the reaction solution was adjusted from 4 to 10 , which was confirmed by the diffraction peaks of HA phase appeared in $\mathrm{M}_{2} \mathrm{~S}-\mathrm{HA}$ scaffolds. However, the diffraction peak intensity increased with the increase of $\mathrm{pH}$ value of the reaction solution, suggesting that the $\mathrm{pH}$ environment could regulate the HA crystallinity during the hydrothermal treatments.

Figure 3 shows SEM images of the surfaces of the $\mathrm{M}_{2} \mathrm{~S}$ and $\mathrm{M}_{2} \mathrm{~S}-\mathrm{HA}$ scaffolds treated at different hydrothermal temperatures. It can be observed that no 

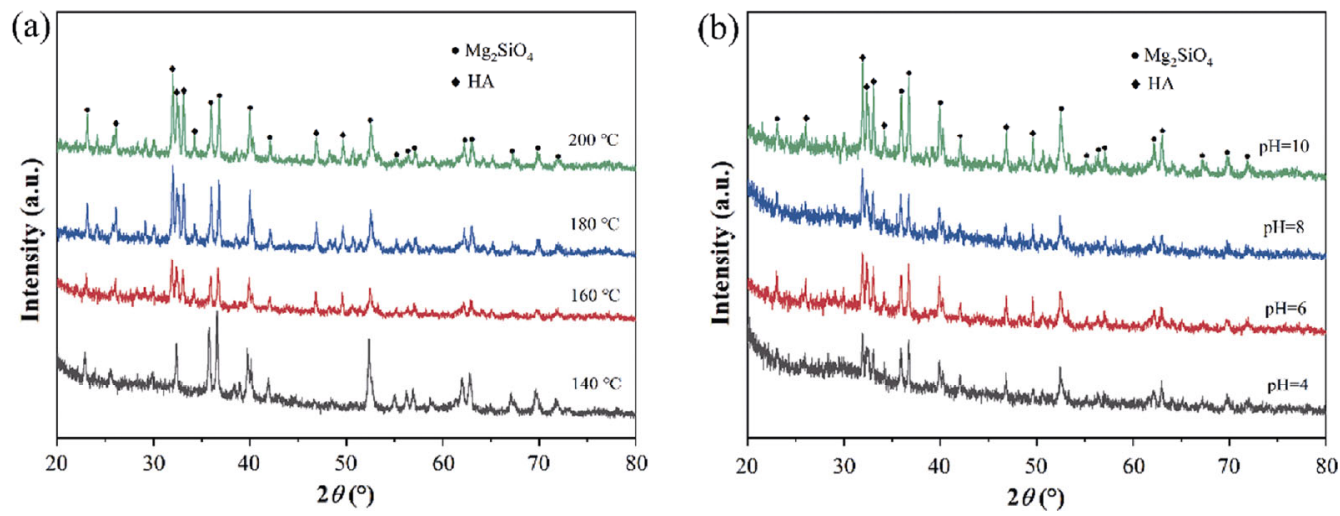

Fig. 2 XRD patterns of $\mathrm{M}_{2} \mathrm{~S}-\mathrm{HA}$ scaffolds obtained under different hydrothermal conditions: (a) different hydrothermal temperatures at $\mathrm{pH}=6$ and (b) different $\mathrm{pH}$ values of the reaction solution at a hydrothermal temperature of $160{ }^{\circ} \mathrm{C}$.
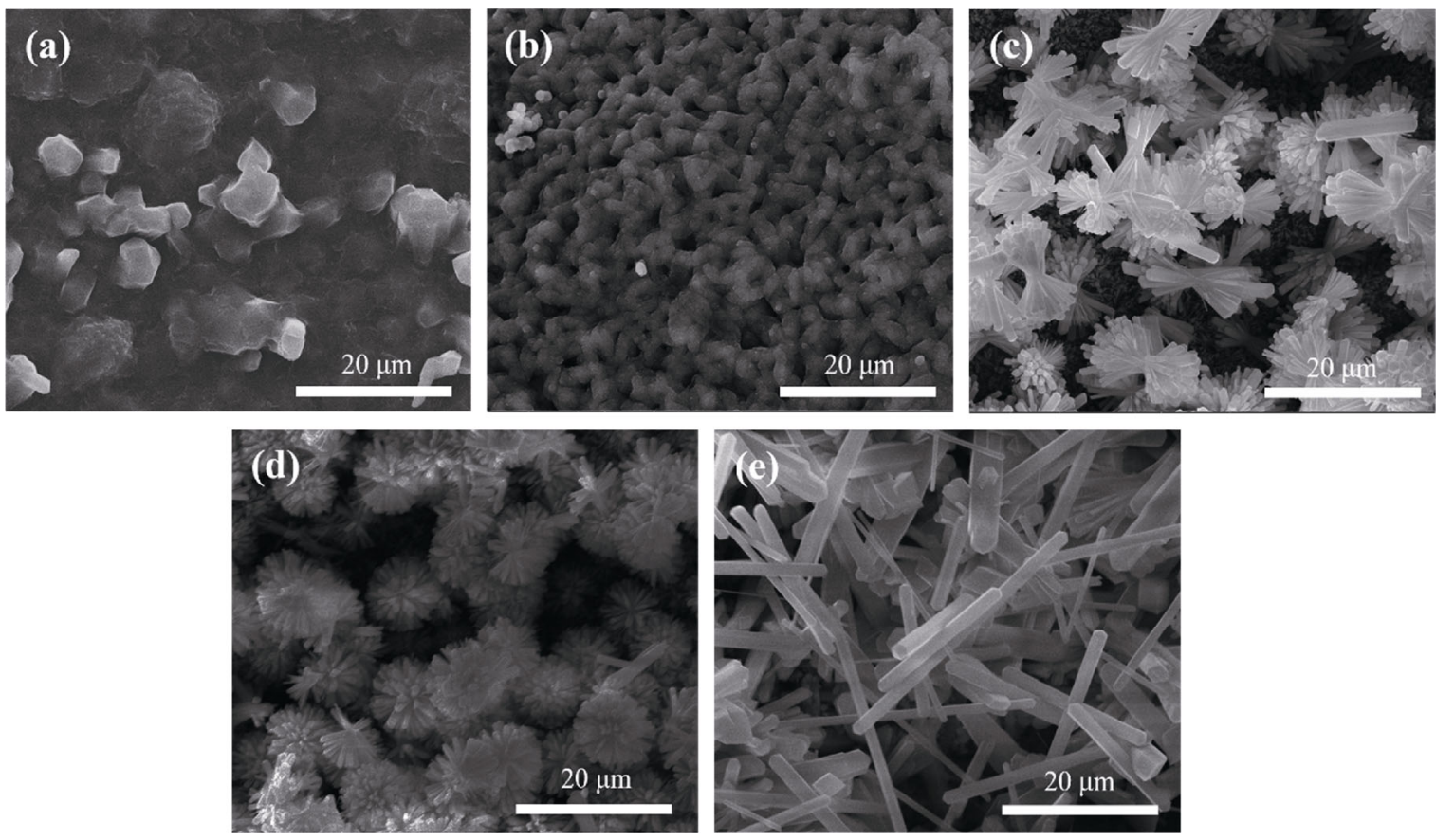

Fig. 3 SEM images of the surfaces of (a) $\mathrm{M}_{2} \mathrm{~S}$ scaffolds; and $\mathrm{M}_{2} \mathrm{~S}-\mathrm{HA}$ scaffolds hydrothermally treated at different hydrothermal temperatures at (b) 140 , (c) 160 , (d) 180 , and (e) $200{ }^{\circ} \mathrm{C}$ when the $\mathrm{pH}$ value of the reaction solution was set to 6 .

HA was covered on the surface of the scaffolds hydrothermally treated at $140{ }^{\circ} \mathrm{C}$, although the surface morphology suffered from a little change due to the dissolution occurrence by hydrothermal treatment. However, different morphological particles were obviously observed on the surfaces of the $\mathrm{M}_{2} \mathrm{~S}-\mathrm{HA}$ scaffolds hydrothermally treated at 160, 180, and $200{ }^{\circ} \mathrm{C}$, which could be identified to be HA particles based on the XRD analysis above. Interestingly, the regular changes of hydrothermal temperature induced different shapes and structures of HA coatings. It can be observed that the hydrothermal temperatures at 160 , 180 , and $200{ }^{\circ} \mathrm{C}$ induced the formation of the flower- like, spherical, or rod-like HA particles on the scaffold surface, respectively. Here, during the hydrothermal process in this study, urea was utilized as an effectual precipitant to adjust the $\mathrm{pH}$ value of the hydrothermal reaction, which promoted the various HA formation. Low hydrothermal temperature $\left(140{ }^{\circ} \mathrm{C}\right)$ was not able to decompose urea, and thereby did not form HA coating. When the hydrothermal temperature raised, the decomposition rate of urea could be accelerated. Thus, the $\mathrm{pH}$ value of the reaction solution slowly increased, which contributed to the formation of HA particles on the surfaces of scaffolds. The higher hydrothermal temperature induced rapid decomposition 
of urea, resulting in the rapid increase of alkalinity in the solution, which accelerated the nucleus formation and growth of HA, and thereby formed diverse morphologies of HA particles on the surfaces of $\mathrm{M}_{2} \mathrm{~S}-\mathrm{HA}$ scaffolds.

Figure 4 shows SEM images of the surfaces of $\mathrm{M}_{2} \mathrm{~S}-\mathrm{HA}$ scaffolds hydrothermally treated at $160{ }^{\circ} \mathrm{C}$ with the $\mathrm{pH}$ values of the reaction solutions from 4 to 10. HA particles could be observed on the surfaces of $\mathrm{M}_{2} \mathrm{~S}-\mathrm{HA}$ scaffolds treated with different $\mathrm{pH}$ values of the reaction solutions. However, the morphology of HA particles changed from spherical to flower-like and rod-like. Furthermore, irregular HA particles were deposited on the scaffolds when the $\mathrm{pH}$ value of the reaction solution was at 4 or 10 , suggesting that the weakly acidic or alkaline environment of the original reaction solution facilitates to form regular HA particles, which was similar to other reported study [32]. On the other hand, the $\mathrm{M}_{2} \mathrm{~S}-\mathrm{HA}$ scaffolds were ultrasonically treated in deionized water bath for $30 \mathrm{~s}$ and rinsed with ethanol, and SEM observation confirmed that the deposited HA particles have not been dropped off from the scaffolds, suggesting that HA particles could stably bond to the surface of the scaffolds.
To investigate the effects of HA coating on the physicochemical and biological performances of $\mathrm{M}_{2} \mathrm{~S}$ scaffolds, the $\mathrm{M}_{2} \mathrm{~S}-\mathrm{HA}$ scaffolds hydrothermally treated with the reaction solution of $\mathrm{pH}=6$ and at hydrothermal temperature of $160{ }^{\circ} \mathrm{C}$ were used in this study. The porosity and compressive strength of the $\mathrm{M}_{2} \mathrm{~S}$ scaffolds before and after HA coating were summarized in Table 1. The compressive strength of $\mathrm{M}_{2} \mathrm{~S}-\mathrm{HA}$ scaffolds was determined to be $32.4 \pm 4.6 \mathrm{MPa}$ at a porosity of $51.5 \% \pm 4.3 \%$, and there are no significant decreases in the porosity and compressive strength of the $\mathrm{M}_{2} \mathrm{~S}$ scaffolds after HA coating, indicating that HA coating process via hydrothermal treatment did not destroy the structure of scaffolds.

Zhu et al. [12] demonstrated that polymer-derived forsterite scaffolds exhibited excellent photothermal performance due to the embedded free carbon. Here, whether the HA coating on the surface of the scaffold will affect the photothermal performance was further confirmed. Figure 5 shows the influence of HA coating on the photothermal effect of scaffolds. It can be seen that both $\mathrm{M}_{2} \mathrm{~S}$ and $\mathrm{M}_{2} \mathrm{~S}-\mathrm{HA}$ scaffolds exhibited excellent photothermal effect under dry (in air) or wet $(500 \mu \mathrm{L}$ PBS) condition with an $808 \mathrm{~nm}$ laser irradiation, and
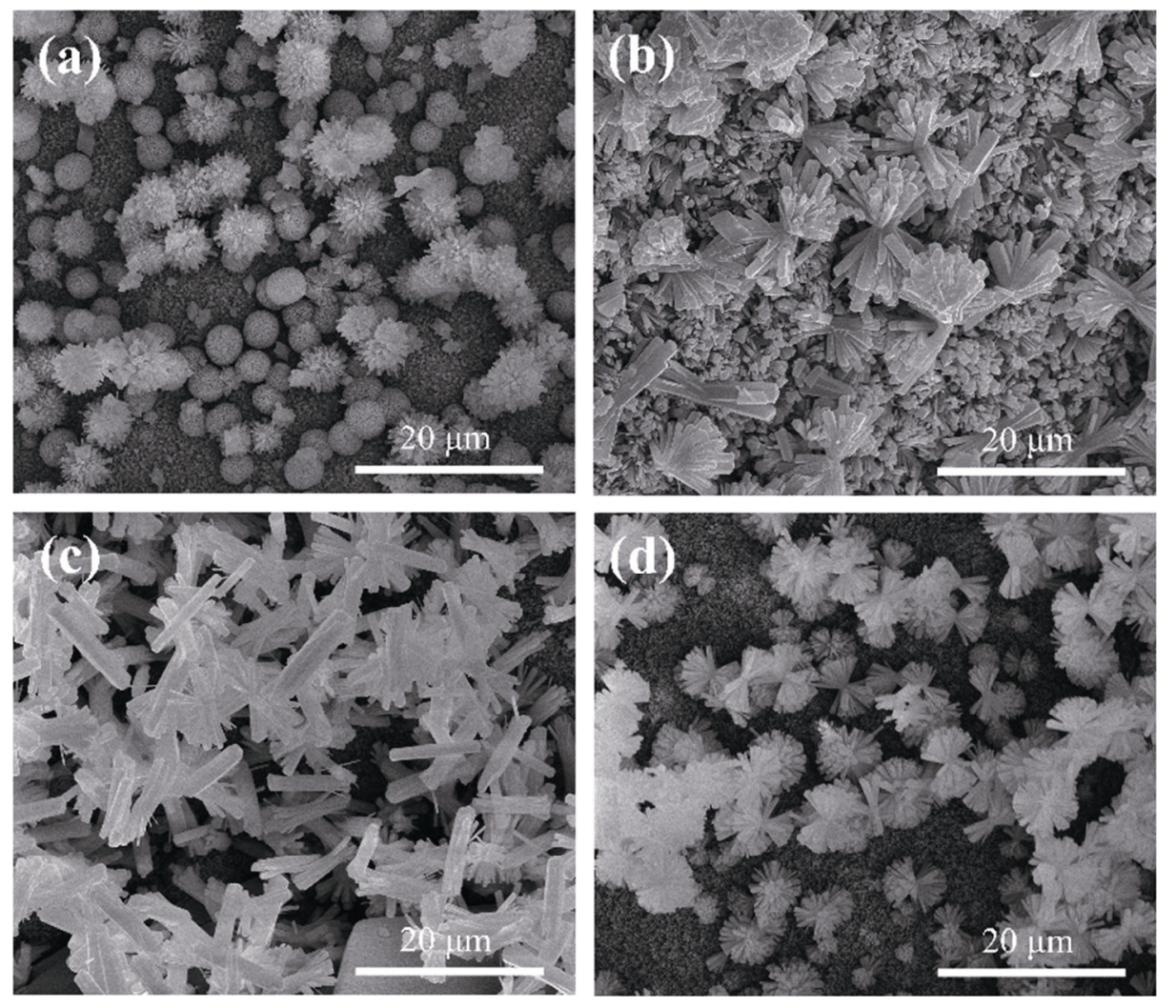

Fig. 4 SEM images of the surfaces of $\mathrm{M}_{2} \mathrm{~S}-\mathrm{HA}$ scaffolds hydrothermally treated at different pH values of (a) 4, (b) 6, (c) 8, and (d) 10 when the hydrothermal temperature was set to $160{ }^{\circ} \mathrm{C}$. 
Table 1 Porosity and compressive strength of $\mathrm{M}_{2} \mathrm{~S}$ and $\mathrm{M}_{2} \mathrm{~S}-\mathrm{HA}$ scaffolds

\begin{tabular}{ccc}
\hline Scaffold & Porosity & Compressive strength (MPa) \\
\hline $\mathrm{M}_{2} \mathrm{~S}$ & $52.7 \% \pm 3.8 \%$ & $33.8 \pm 5.1$ \\
$\mathrm{M}_{2} \mathrm{~S}-\mathrm{HA}$ & $51.5 \% \pm 4.3 \%$ & $32.4 \pm 4.6$ \\
\hline
\end{tabular}

there are negligible changes after HA coating on $\mathrm{M}_{2} \mathrm{~S}$ scaffolds. After laser irradiation with an $808 \mathrm{~nm}$ laser at a power density of $0.75 \mathrm{~W} / \mathrm{cm}^{2}$ for $5 \mathrm{~min}$, the surface temperatures of both $\mathrm{M}_{2} \mathrm{~S}$ and $\mathrm{M}_{2} \mathrm{~S}-\mathrm{HA}$ scaffolds in dry condition increased from room temperature to above $100{ }^{\circ} \mathrm{C}$, and the solution temperatures of both $\mathrm{M}_{2} \mathrm{~S}$ and $\mathrm{M}_{2} \mathrm{~S}-\mathrm{HA}$ scaffolds in wet condition could still increase
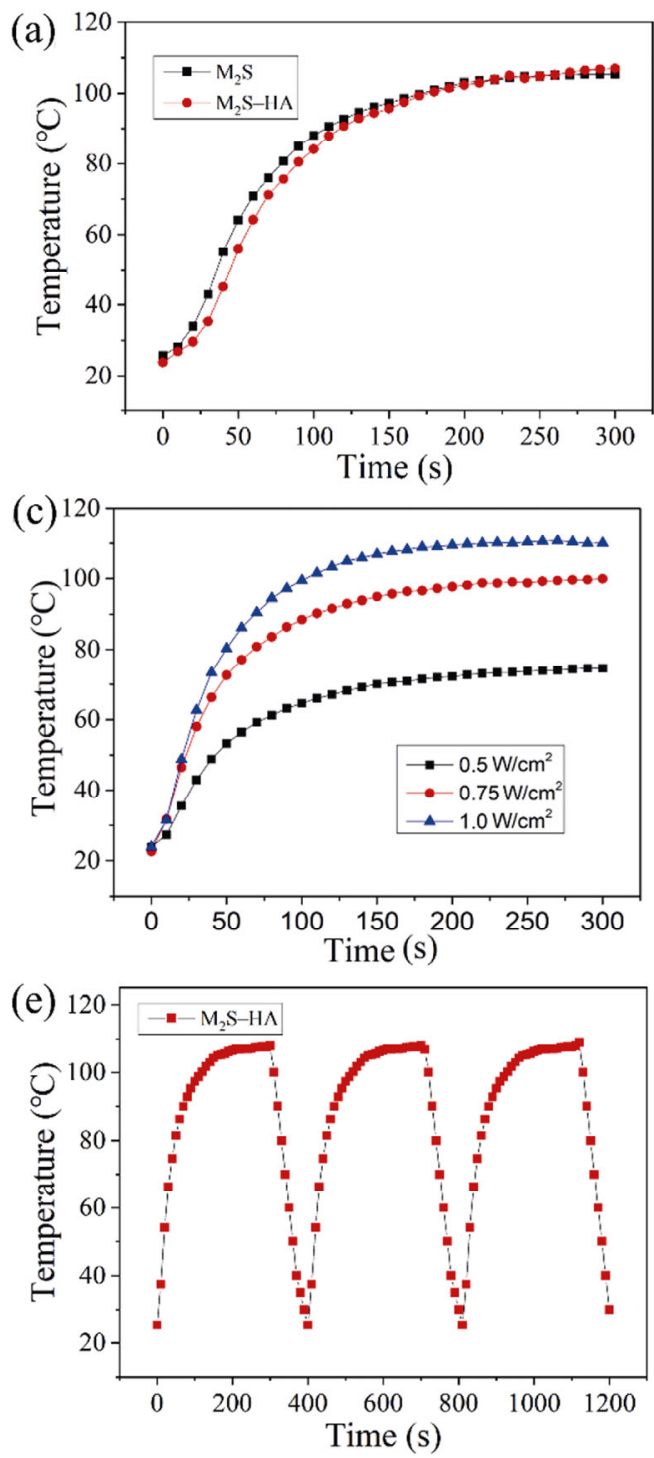

to above $50{ }^{\circ} \mathrm{C}$. Here, the photothermal effect of the $\mathrm{M}_{2} \mathrm{~S}$ and $\mathrm{M}_{2} \mathrm{~S}-\mathrm{HA}$ scaffolds were determined by the free carbon content in the scaffolds. We have detected the carbon element of the cross section of the $\mathrm{M}_{2} \mathrm{~S}$ and $\mathrm{M}_{2} \mathrm{~S}-\mathrm{HA}$ scaffolds by energy disperse spectroscopy (EDS) analysis, and the carbon contents were estimated to be $10.37 \%$ and $10.68 \%$, respectively. It indicated that HA coating did not influence the photothermal effect of $\mathrm{M}_{2} \mathrm{~S}$ scaffolds. Hence, the $\mathrm{M}_{2} \mathrm{~S}-\mathrm{HA}$ scaffolds had photothermal antibacterial ability. Furthermore, the temperature of $\mathrm{M}_{2} \mathrm{~S}-\mathrm{HA}$ scaffolds caused by the photothermal effect increased with the increase of laser power density, suggesting that the photothermal
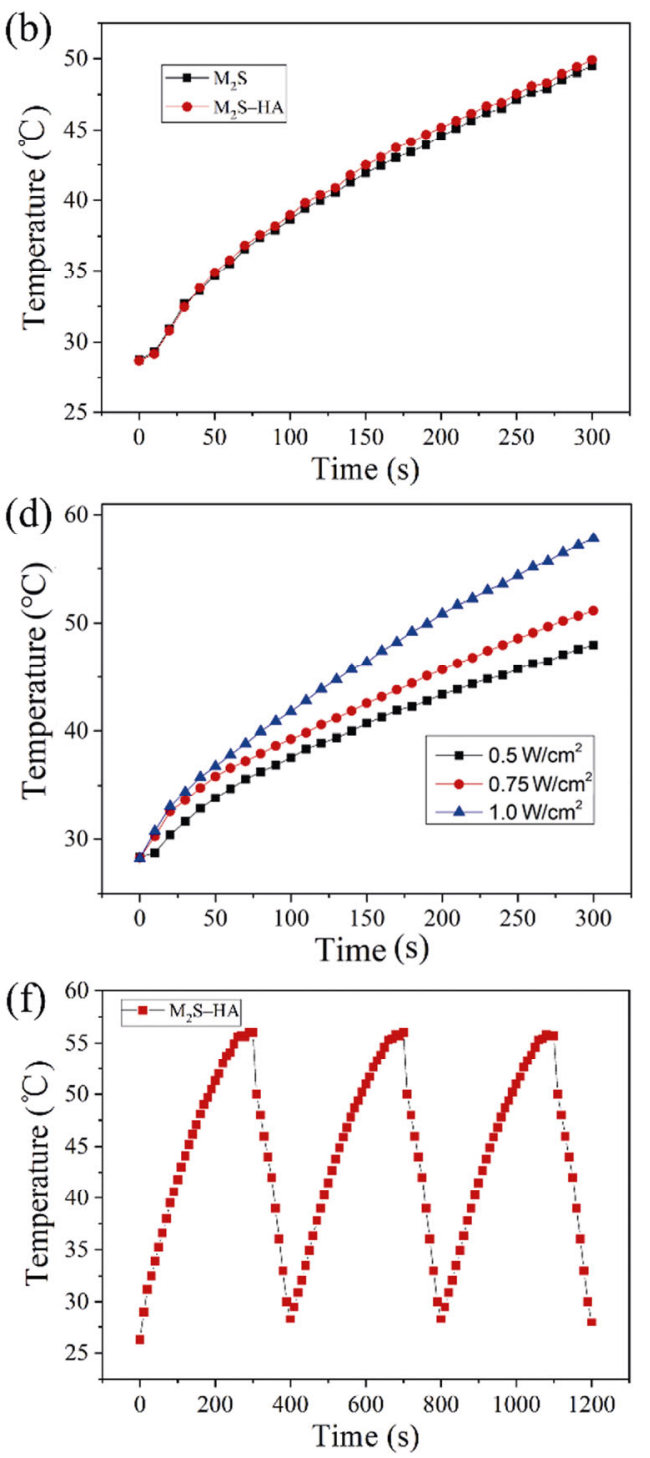

Fig. 5 Photothermal heating curves of both $\mathrm{M}_{2} \mathrm{~S}$ and $\mathrm{M}_{2} \mathrm{~S}-\mathrm{HA}$ scaffolds in (a) dry and (b) wet conditions under an $808 \mathrm{~nm}$ laser irradiation with a power density of $0.75 \mathrm{~W} / \mathrm{cm}^{2}$. The photothermal heating curves of $\mathrm{M}_{2} \mathrm{~S}-\mathrm{HA}$ scaffolds in (c) dry and (d) wet conditions under an $808 \mathrm{~nm}$ laser irradiation with different laser power densities $\left(0.5,0.75\right.$, and $\left.1.0 \mathrm{~W} / \mathrm{cm}^{2}\right)$. The time-temperature curve of the laser "on-off" cycle $\left(0.75 \mathrm{~W} / \mathrm{cm}^{2}\right)$ of $\mathrm{M}_{2} \mathrm{~S}-\mathrm{HA}$ scaffolds in (e) dry and (f) wet conditions under an $808 \mathrm{~nm}$ laser irradiation. 
temperature of $\mathrm{M}_{2} \mathrm{~S}-\mathrm{HA}$ scaffolds could be controlled by adjusting the laser power density to meet the photothermal antibacterial temperature (Figs. 5(c) and 5(d)). On the other hand, an $808 \mathrm{~nm}$ laser with a power density of $0.75 \mathrm{~W} / \mathrm{cm}^{2}$ was utilized to irradiate the $\mathrm{M}_{2} \mathrm{~S}$-HA scaffolds for $5 \mathrm{~min}$ (turn on), followed by a cooling process to room temperature (turn off), and three "on-off" cycles were performed. As shown in Figs. 5(e) and 5(f), the increased temperature of $\mathrm{M}_{2} \mathrm{~S}-\mathrm{HA}$ scaffolds after each "on-off" cycle did not significantly decrease, whatever in dry or wet condition, which indicated that the $\mathrm{M}_{2} \mathrm{~S}-\mathrm{HA}$ scaffolds had remarkable photothermal stability, and showed a great potential for long-term photothermal antibacterial function.

The cell adhesion and in vitro osteogenic activity of $\mathrm{M}_{2} \mathrm{~S}-\mathrm{HA}$ scaffolds were investigated to confirm if HA coating could enhance the bioactivity of $\mathrm{M}_{2} \mathrm{~S}$ scaffolds. The adhesion of rBMSCs on both $\mathrm{M}_{2} \mathrm{~S}$ and $\mathrm{M}_{2} \mathrm{~S}-\mathrm{HA}$ scaffolds were visualized by confocal laser scanning microscopy (CLSM). As shown in Fig. 6(a), the dense and uniform layers of rBMSCs with a typical cytoskeleton morphology were distributed on both scaffolds after 3-day culture, which indicated that rBMSCs were well adhered on both scaffolds, and the interconnected porous structure facilitated cell migration and further proliferation.

Figure 6(b) shows the proliferation of rBMSCs on both $\mathrm{M}_{2} \mathrm{~S}$ and $\mathrm{M}_{2} \mathrm{~S}-\mathrm{HA}$ scaffolds for 1, 3, and 7 days. With increasing culture time, the number of rBMSCs on both $\mathrm{M}_{2} \mathrm{~S}$ and $\mathrm{M}_{2} \mathrm{~S}-\mathrm{HA}$ scaffolds increased significantly. However, both $\mathrm{M}_{2} \mathrm{~S}$ and $\mathrm{M}_{2} \mathrm{~S}-\mathrm{HA}$ scaffolds showed similar level of cell proliferation at each culture time point, revealing the good biocompatibility for both $\mathrm{M}_{2} \mathrm{~S}$ and $\mathrm{M}_{2} \mathrm{~S}-\mathrm{HA}$ scaffolds. Here, the OD value for the $\mathrm{M}_{2} \mathrm{~S}-\mathrm{HA}$ scaffold group showed a little decrease compared to that for the $\mathrm{M}_{2} \mathrm{~S}$ scaffold group, but both groups had no significant difference, suggesting that HA coating did not influence the biocompatibility of the scaffolds. ALP activity of rBMSCs on both $\mathrm{M}_{2} \mathrm{~S}$ and $\mathrm{M}_{2} \mathrm{~S}-\mathrm{HA}$ scaffolds was further evaluated to assess the early differentiation of osteoblasts. As shown in Fig. 6(c), the level of ALP activity increased with culture time, and both $\mathrm{M}_{2} \mathrm{~S}$ and $\mathrm{M}_{2} \mathrm{~S}-\mathrm{HA}$ scaffolds showed higher level of ALP activity than the blank group. (a)
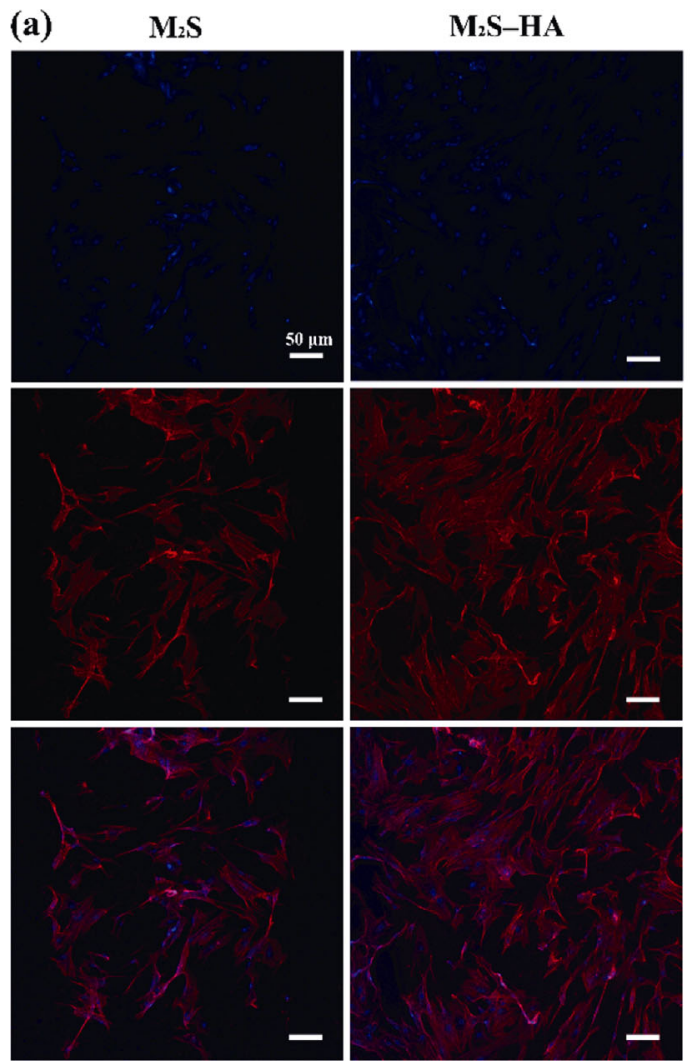

(b)
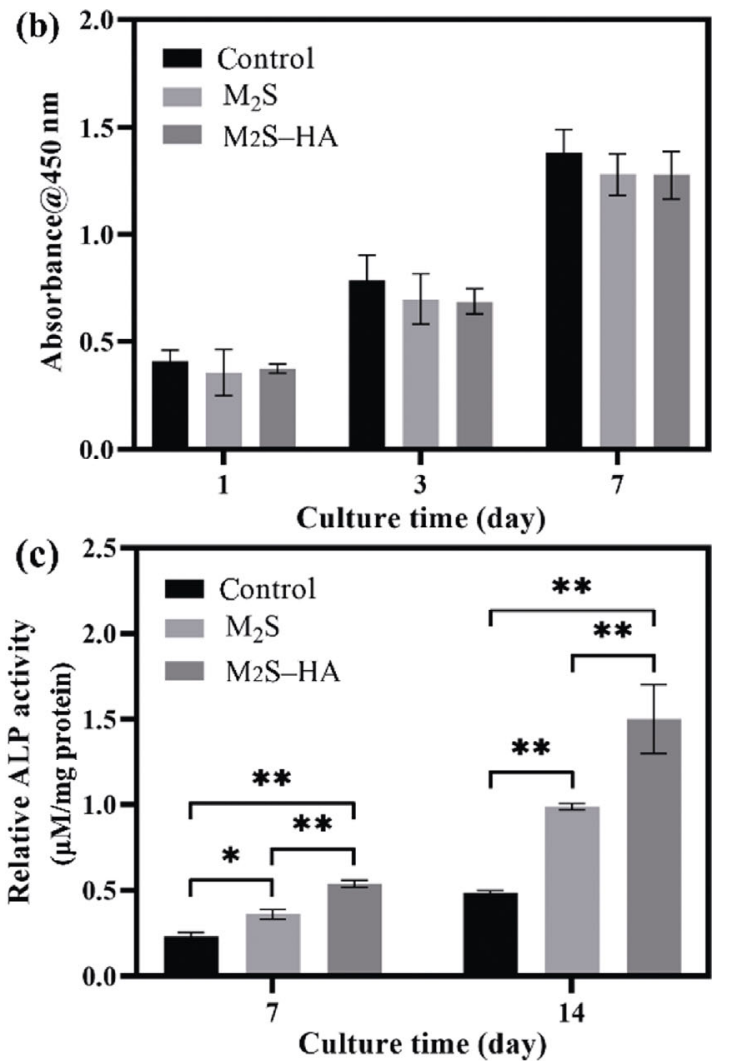

Fig. 6 In vitro cellular response on the $\mathrm{M}_{2} \mathrm{~S}$ and $\mathrm{M}_{2} \mathrm{~S}-\mathrm{HA}$ scaffolds. (a) CLSM images of rBMSCs seeded on the $\mathrm{M}_{2} \mathrm{~S}$ and $\mathrm{M}_{2} \mathrm{~S}-\mathrm{HA}$ scaffolds for 3 days (scale bar: $50 \mu \mathrm{m}$ ); (b) proliferation of rBMSCs cultured on the $\mathrm{M}_{2} \mathrm{~S}$ and $\mathrm{M}_{2} \mathrm{~S}-\mathrm{HA}$ scaffolds for 1, 3 , and 7 days; (c) ALP activity of rBMSCs cultured on the $\mathrm{M}_{2} \mathrm{~S}$ and $\mathrm{M}_{2} \mathrm{~S}-\mathrm{HA}$ scaffolds for 7 and 14 days $\left({ }^{*} P<0.05,{ }^{* *} P<0.01\right)$. 
Furthermore, the ALP activity of rBMSCs on $\mathrm{M}_{2} \mathrm{~S}-\mathrm{HA}$ scaffolds was much higher than that on $\mathrm{M}_{2} \mathrm{~S}$ scaffolds. It indicated that HA coating on $\mathrm{M}_{2} \mathrm{~S}$ scaffolds could improve the bioactivity of scaffolds and promote the early osteogenic differentiation of rBMSCs [33].

To further evaluate the osteogenic differentiation of rBMSCs on the $\mathrm{M}_{2} \mathrm{~S}$ and $\mathrm{M}_{2} \mathrm{~S}-\mathrm{HA}$ scaffolds, the expression of osteogenic related genes of rBMSCs (COL-1, OCN, ALP, and RUNX2) on both $\mathrm{M}_{2} \mathrm{~S}$ and $\mathrm{M}_{2} \mathrm{~S}-\mathrm{HA}$ scaffolds was tested in this study. GAPDH was used as the internal reference for standardization. Primers (BioTNT, Shanghai, China) used for the amplification reaction are listed in Table 2. Figure 7 shows the expression of osteogenic related genes of rBMSCs on the scaffolds after 7-day culture. The expression levels of COL-1, OCN, ALP, and RUNX2 genes on the $\mathrm{M}_{2} \mathrm{~S}$ and $\mathrm{M}_{2} \mathrm{~S}-\mathrm{HA}$ scaffolds were much higher compared to blank group, suggesting that both scaffolds could promote the expression of osteogenic related genes. More importantly, $\mathrm{M}_{2} \mathrm{~S}-\mathrm{HA}$ scaffolds showed much higher expression level of osteogenic related genes than $\mathrm{M}_{2} \mathrm{~S}$ scaffolds, which indicated that HA coating on $\mathrm{M}_{2} \mathrm{~S}$ scaffolds could improve the osteogenic differentiation. Previous studies also demonstrated that HA coating as a bioactive surface could enhance cell attachment, proliferation, and osteogenic differentiation of stem cells in vitro [34].

It has demonstrated that $\mathrm{M}_{2} \mathrm{~S}$ scaffolds had excellent photothermal-induced antibacterial activity due to the embedded free carbon with photothermal effect [12]. Here, using S. aureus and E. coli as Gram-positive and Gram-negative bacteria, respectively, the photothermalinduced antibacterial activity of the $\mathrm{M}_{2} \mathrm{~S}-\mathrm{HA}$ scaffolds was also evaluated by dilution plate counting method. As shown in Fig. 8, after 15 min of irradiation with an $808 \mathrm{~nm}$ laser irradiation, the number of viable bacterial colonies of the samples containing $\mathrm{M}_{2} \mathrm{~S}-\mathrm{HA}$ scaffolds on the AGAR plates decreased significantly, and the

Table 2 Primer sequences used for qPCR

\begin{tabular}{ccc}
\hline Gene & Forward primer sequence (5'-3') & Reverse primer sequence $\left(5^{\prime}\right.$ ' $^{\prime}$ ') \\
\hline ALP & CAAGGATGCTGGGAAGTCCG & CTCTGGGCGCATCTCATTGT \\
RUNX2 & CCGAGACCAACCGAGTCATTTA & AAGAGGCTGTTTGACGCCAT \\
OCN & TCAACAATGGACTTGGAGCCC & AGCTCGTCACAATTGGGGTT \\
COL-1 & GGAGAGTACTGGATCGACCCTAAC & CTGACCTGTCTCCATGTTGCA \\
GAPDH & GAAGGTGAAGGTCGGAGTC & GAAGATGGTGATGGGATTTC \\
\hline
\end{tabular}
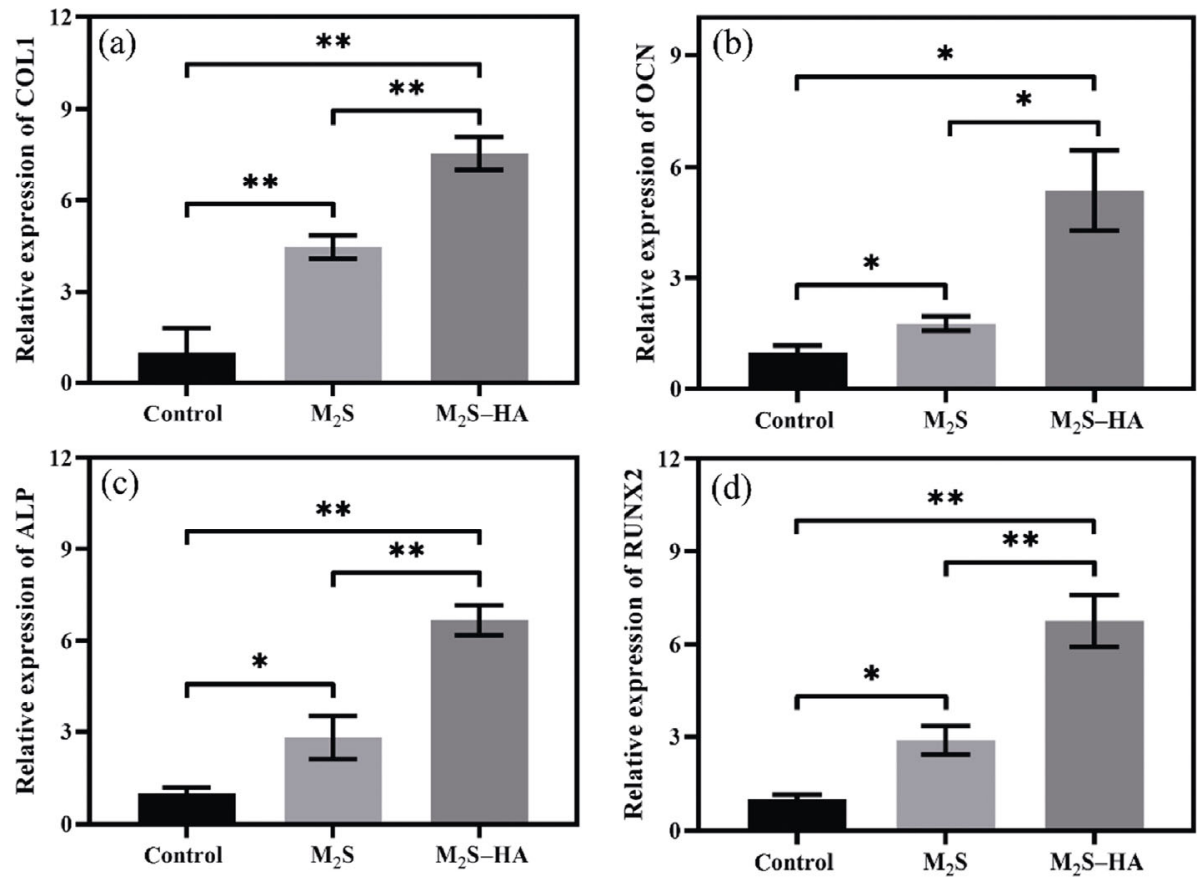

Fig. 7 Osteogenesis-related gene expression of (a) COL-1, (b) OCN, (c) ALP, and (d) RUNX2 for rBMSCs cultured on the $\mathrm{M}_{2} \mathrm{~S}$ and $\mathrm{M}_{2} \mathrm{~S}-\mathrm{HA}$ scaffolds for 7 days by qPCR analysis $\left({ }^{*} P<0.05,{ }^{* *} P<0.01\right)$. 
(a)

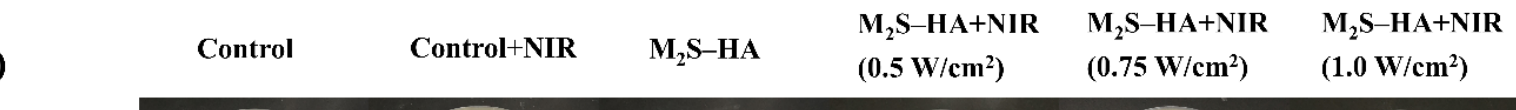

S. aureus

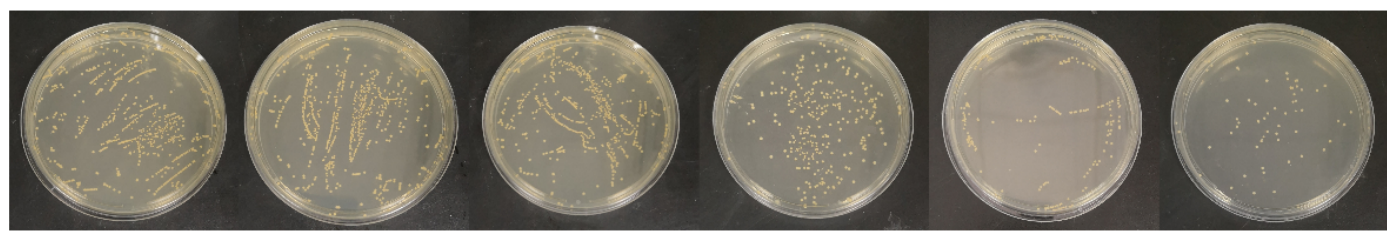

E. coli

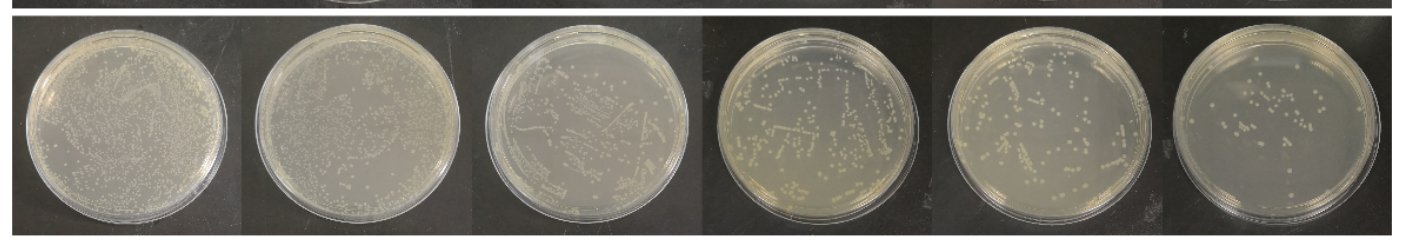

(b)

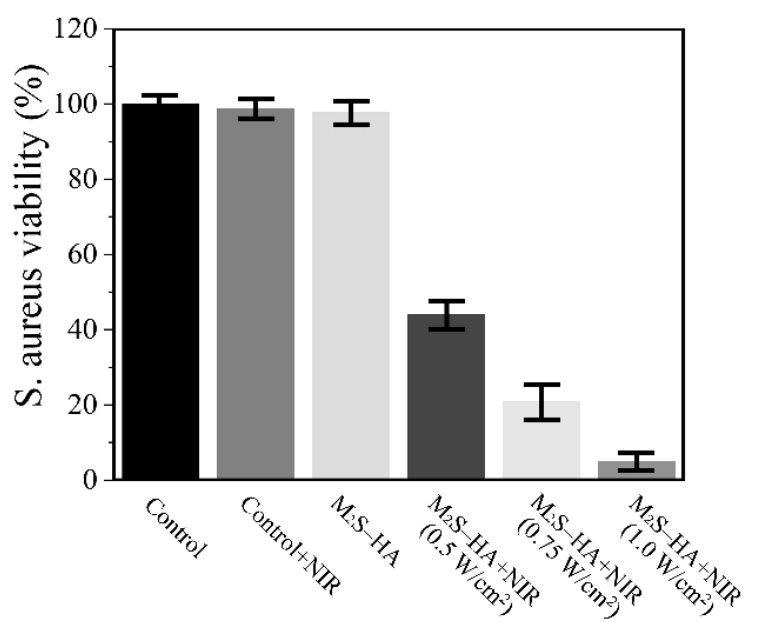

(c)

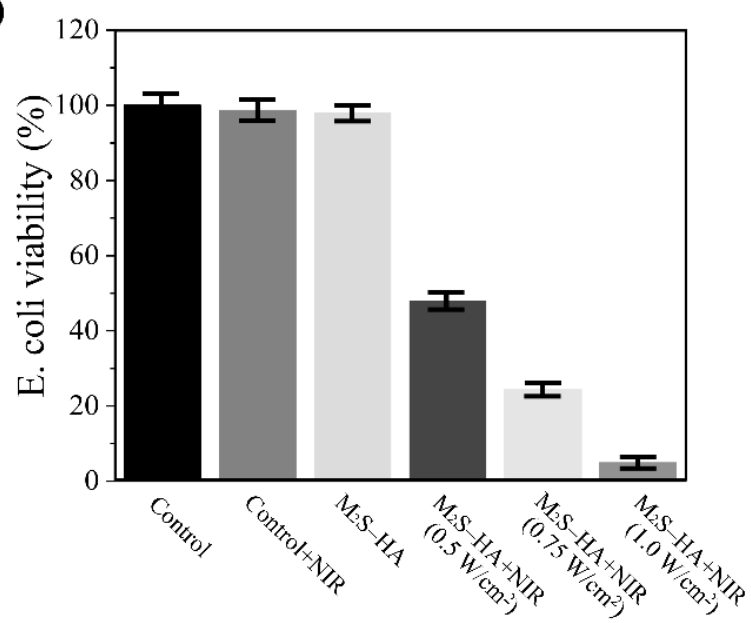

Fig. 8 In vitro photothermal-induced antibacterial ability of the $\mathrm{M}_{2} \mathrm{~S}-\mathrm{HA}$ scaffolds. (a) Optical images of S. aureus and E. coli colonies formed on AGAR plates after different treatments; bacterial colony viability of (b) S. aureus and (c) E. coli after different treatments.

antibacterial efficiency increased with increasing the laser power density. It can be observed that the antibacterial efficiencies of $\mathrm{M}_{2} \mathrm{~S}-\mathrm{HA}$ scaffolds against S. aureus and E. coli were $57.7 \%$ and $51.9 \%$ after $0.5 \mathrm{~W} / \mathrm{cm}^{2}$ laser irradiation for $15 \mathrm{~min}$, respectively. However, when the laser power density was increased to $1.0 \mathrm{~W} / \mathrm{cm}^{2}$, the antibacterial efficiencies of $\mathrm{M}_{2} \mathrm{~S}-\mathrm{HA}$ scaffolds against $\mathrm{S}$. aureus and $\mathrm{E}$. coli were significantly enhanced, even up to $96.1 \%$ and $95.6 \%$, respectively, which showed similar antibacterial efficiencies for the $\mathrm{M}_{2} \mathrm{~S}$ and $\mathrm{M}_{2} \mathrm{~S}-\mathrm{HA}$ scaffolds at the same irradiation conditions [12]. Therefore, $\mathrm{M}_{2} \mathrm{~S}-\mathrm{HA}$ scaffolds still had excellent photothermal antibacterial ability, and the antibacterial efficiency could be regulated by controlling the laser power density.

HA coating did not influence the photothermal effect of the $\mathrm{M}_{2} \mathrm{~S}$ scaffolds, and thereby endowed the $\mathrm{M}_{2} \mathrm{~S}-\mathrm{HA}$ scaffolds with excellent photothermal-induced antibacterial activity. On the other hand, HA coating on the $\mathrm{M}_{2} \mathrm{~S}$ scaffolds promoted the osteogenic differentiation of
rBMSCs due to the enhanced bioactivity. Hence, $\mathrm{M}_{2} \mathrm{~S}-\mathrm{HA}$ scaffolds show great potential for bone repair against bacterial infection.

\section{Conclusions}

In summary, forsterite-HA composite scaffolds with photothermal-induced antibacterial ability have been successfully fabricated through HA deposition on 3D-printed polymer-derived forsterite scaffolds via a hydrothermal method. The morphology of HA coating could be regulated by controlling the hydrothermal temperature and $\mathrm{pH}$ value of the reaction solution. The HA-coated forsterite scaffolds not only dramatically boosted the proliferation and promoted osteogenic differentiation of rBMSCs on the $\mathrm{M}_{2} \mathrm{~S}-\mathrm{HA}$, but also maintained excellent photothermal-induced antibacterial ability under an $808 \mathrm{~nm}$ laser irradiation. Therefore, such HA-coated forsterite scaffolds showed great 
potential for bacterial infected bone repair.

\section{Acknowledgements}

This work was supported by the National Natural Science Foundation of China (Nos. 51872185, 51972212, and 52072246) and Shanghai Natural Science Foundation (No. 19ZR1435100).

\section{References}

[1] Turnbull G, Clarke J, Picard F, et al. 3D bioactive composite scaffolds for bone tissue engineering. Bioact Mater 2018, 3: 278-314.

[2] Alonzo M, Alvarez P F, Anil K S, et al. Bone tissue engineering techniques, advances, and scaffolds for treatment of bone defects. Curr Opin Biomed Eng 2021, 17: 100248.

[3] Pei P, Wei DX, Zhu M, et al. The effect of calcium sulfate incorporation on physiochemical and biological properties of 3D-printed mesoporous calcium silicate cement scaffolds. Microporous Mesoporous Mater 2017, 241: 11-20.

[4] Myat-Htun M, Mohd Noor AF, Kawashita M, et al. Enhanced sinterability and in vitro bioactivity of bariumdoped akermanite ceramic. Ceram Int 2020, 46: 19062-19068.

[5] Keihan R, Ghorbani AR, Salahinejad E, et al. Biomineralization, strength and cytocompatibility improvement of bredigite scaffolds through doping/coating. Ceram Int 2020, 46: 21056-21063.

[6] Jones JR. Review of bioactive glass: From Hench to hybrids. Acta Biomater 2013, 9: 4457-4486.

[7] Ramesh S, Yaghoubi A, Lee KYS, et al. Nanocrystalline forsterite for biomedical applications: Synthesis, microstructure and mechanical properties. J Mech Behav Biomed Mater 2013, 25: 63-69.

[8] Choudhary R, Chatterjee A, Venkatraman SK, et al. Antibacterial forsterite $\left(\mathrm{Mg}_{2} \mathrm{SiO}_{4}\right)$ scaffold: A promising bioceramic for load bearing applications. Bioact Mater 2018, 3: 218-224.

[9] Krishnamurithy G, Mohan S, Yahya NA, et al. The physicochemical and biomechanical profile of forsterite and its osteogenic potential of mesenchymal stromal cells. PLoS One 2019, 14: e0214212.

[10] Tavangarian F, Fahami A, Li GQ, et al. Structural characterization and strengthening mechanism of forsterite nanostructured scaffolds synthesized by multistep sintering method. J Mater Sci Technol 2018, 34: 2263-2270.

[11] Fu SY, Zhu M, Zhu YF. Organosilicon polymer-derived ceramics: An overview. J Adv Ceram 2019, 8: 457-478.

[12] Zhu TL, Zhu M, Zhu YF. Fabrication of forsterite scaffolds with photothermal-induced antibacterial activity by $3 \mathrm{D}$ printing and polymer-derived ceramics strategy. Ceram Int 2020, 46: 13607-13614.

[13] $\mathrm{Fu} \mathrm{SY,} \mathrm{Hu} \mathrm{HR,} \mathrm{Chen} \mathrm{JJ,} \mathrm{et} \mathrm{al.} \mathrm{Silicone} \mathrm{resin} \mathrm{derived}$ larnite/C scaffolds via $3 \mathrm{D}$ printing for potential tumor therapy and bone regeneration. Chem Eng $J$ 2020, 382: 122928.

[14] Tavangarian F, Emadi R. Improving degradation rate and apatite formation ability of nanostructure forsterite. Ceram Int 2011, 37: 2275-2280.

[15] Saidi R, Fathi M, Salimijazi H. Synthesis and characterization of bioactive glass coated forsterite scaffold for tissue engineering applications. J Alloys Compd 2017, 727: 956-962.

[16] Naghieh S, Foroozmehr E, Badrossamay M, et al. Combinational processing of 3D printing and electrospinning of hierarchical poly(lactic acid)/gelatin-forsterite scaffolds as a biocomposite: Mechanical and biological assessment. Mater Des 2017, 133: 128-135.

[17] Lim HK, Byun SH, Lee JY, et al. Radiological, histological, and hematological evaluation of hydroxyapatite-coated resorbable magnesium alloy screws placed in rabbit tibia. $J$ Biomed Mater Res B: Appl Biomater 2017, 105: 16361644.

[18] Wen ZH, Zhang LM, Chen C, et al. A construction of novel iron-foam-based calcium phosphate/chitosan coating biodegradable scaffold material. Mater Sci Eng C Mater Biol Appl 2013, 33: 1022-1031.

[19] Huan YC, Wu KD, Li CJ, et al. Micro-nano structured functional coatings deposited by liquid plasma spraying. $J$ Adv Ceram 2020, 9: 517-534.

[20] Um SH, Chung YW, Seo Y, et al. Robust hydroxyapatite coating by laser-induced hydrothermal synthesis. $A d v$ Funct Mater 2020, 30: 2005233.

[21] Ripamonti U, Crooks J, Khoali L, et al. The induction of bone formation by coral-derived calcium carbonate/ hydroxyapatite constructs. Biomaterials 2009, 30: 1428-1439.

[22] Liu HR, Xia LL, Dai Y, et al. Fabrication and characterization of novel hydroxyapatite/porous carbon composite scaffolds. Mater Lett 2012, 66: 36-38.

[23] Liu JB, Ye XY, Wang H, et al. The influence of $\mathrm{pH}$ and temperature on the morphology of hydroxyapatite synthesized by hydrothermal method. Ceram Int 2003, 29: 629-633.

[24] Chen HF, Tang ZY, Liu J, et al. Acellular synthesis of a human enamel-like microstructure. Adv Mater 2006, 18: 1846-1851.

[25] Zhang CM, Yang J, Quan ZW, et al. Hydroxyapatite nanoand micro-crystals with multiform morphologies: Controllable synthesis and luminescence properties. Cryst Growth Des 2009, 9: 2725-2733.

[26] Chen W, Long T, Guo YJ, et al. Magnetic hydroxyapatite coatings with oriented nanorod arrays: Hydrothermal synthesis, structure and biocompatibility. J Mater Chem B 2014, 2: 1653.

[27] Yang C, Huan ZG, Wang XY, et al. 3D printed Fe scaffolds with HA nanocoating for bone regeneration. ACS Biomater Sci Eng 2018, 4: 608-616.

[28] Hu JZ, Zhou YC, Huang LH, et al. Effect of 
nano-hydroxyapatite coating on the osteoinductivity of porous biphasic calcium phosphate ceramics. BMC Musculoskelet Disord 2014, 15: 114.

[29] Gloria A, Russo T, D'Amora U, et al. Magnetic poly( $\varepsilon$-caprolactone)/iron-doped hydroxyapatite nanocomposite substrates for advanced bone tissue engineering. $J R$ Soc Interface 2013, 10: 20120833.

[30] Yang JC, Zhang J, Ding C, et al. Regulation of osteoblast differentiation and iron content in MC3T3-E1 cells by static magnetic field with different intensities. Biol Trace Elem Res 2018, 184: 214-225.

[31] Wiedmer D, Cui C, Weber F, et al. Antibacterial surface coating for bone scaffolds based on the dark catalytic effect of titanium dioxide. ACS Appl Mater Interfaces 2018, 10: 35784-35793.

[32] In Y, Amornkitbamrung U, Hong $\mathrm{MH}$, et al. On the crystallization of hydroxyapatite under hydrothermal conditions: Role of sebacic acid as an additive. ACS Omega 2020, 5: 27204-27210.

[33] Cui BC, Zhang RR, Sun FB, et al. Mechanical and biocompatible properties of polymer-infiltrated-ceramic- network materials for dental restoration. J Adv Ceram 2020, 9: $123-128$.

[34] Yang C, Wang XY, Ma B, et al. 3D-printed bioactive $\mathrm{Ca}_{3} \mathrm{SiO}_{5}$ bone cement scaffolds with nano surface structure for bone regeneration. ACS Appl Mater Interfaces 2017, 9: $5757-5767$.

Open Access This article is licensed under a Creative Commons Attribution 4.0 International License, which permits use, sharing, adaptation, distribution and reproduction in any medium or format, as long as you give appropriate credit to the original author(s) and the source, provide a link to the Creative Commons licence, and indicate if changes were made.

The images or other third party material in this article are included in the article's Creative Commons licence, unless indicated otherwise in a credit line to the material. If material is not included in the article's Creative Commons licence and your intended use is not permitted by statutory regulation or exceeds the permitted use, you will need to obtain permission directly from the copyright holder.

To view a copy of this licence, visit http://creativecommons. org/licenses/by/4.0/. 